\title{
POTENCIAL ACARICIDA DO EXTRATO ETANÓLICO DE Sapindus saponaria E DE SOLUÇÃO SABÃO SOBRE Tetranychus urticae
}

\author{
ACARICIDAL POTENTIAL OF ETHANOLIC EXTRACT FROM Sapindus \\ saponaria AND SOAP SOLUTION AGAINST Tetranychus urticae
}

\begin{abstract}
Victor Bernardo VICENTINI ${ }^{1}$; Dirceu PRATISSOLI' ${ }^{2}$ Adilson Vidal COSTA ${ }^{3}$; Vagner Tebaldi de QUEIROZ ${ }^{3}$; Fernando Domingo ZINGER ${ }^{1}$; Patrícia Fontes PINHEIRO ${ }^{3}$

1. Mestre, Departamento de Produção Vegetal, Centro de Ciências Agrárias da Universidade Federal do Espírito Santo - UFES, Alegre, Espírito Santo, Brasil. victorbvicentini@ @otmail.com; 2. Professor, Doutor, Departamento de Produção Vegetal, Centro de Ciências Agrárias - UFES, Alegre, Espírito Santo; 3. Professor, Doutor, Departamento de Química e Física, Centro de Ciências Agrárias - UFES, Alegre, Espírito Santo, Brasil.
\end{abstract}

\begin{abstract}
RESUMO: Tetranychus urticae Koch (1836) (Acari: Tetranychidae), conhecido como ácaro rajado, é uma praga que pode reduzir a produção de frutos do morangueiro em até $80 \%$. O controle desta praga por meio de acaricidas sintéticos tem proporcionado à destruição de organismos benéficos e o desenvolvimento de populações resistentes. Como alternativa ao controle tradicional, este trabalho teve como objetivo avaliar os efeitos do extrato de Sapindus saponaria e de solução sabão sobre a oviposição e mortalidade de fêmeas de T. urticae. Os ácaros foram pulverizados, com auxílio da Torre de Potter, usando formulações do extrato/solução sabão a 1, 2, 3, 4, 5\% (m/v) e avaliados em 24,72 e $120 \mathrm{~h}$. Verificou-se que o extrato de $S$. saponaria apresentou maior eficiência $\left(\mathrm{CL}_{50}, 1,18 \%\right)$ do que a solução sabão $\left(\mathrm{CL}_{50}\right.$, $1,31 \%)$. Em relação à atividade ovicida, o maior efeito foi observado com a formulação a 5\% (m/v) após $120 \mathrm{~h}$, tanto para o extrato de $S$. saponaria $(60,9 \%)$ quanto para solução sabão $(84 \%)$. Os resultados observados, em condições de laboratório, são favoráveis à utilização do extrato de $S$. saponaria e de solução sabão no controle de $T$. urticae em programas de manejo fitossanitário para a cultura do morango.
\end{abstract}

PALAVRAS-CHAVE: Saponácea. Ácaro rajado. Planta inseticida. Sabão.

\section{INTRODUÇÃO}

Os ácaros (Acari: Arachnida) pertencem ao grupo mais heterogêneo de aracnídeos, pois apresentam enorme diversidade de espécies em relação aos hábitos alimentares e hábitats. Dentre os ácaros fitófagos, o ácaro rajado é considerado praga para inúmeras culturas economicamente importantes em todo o mundo, como o morangueiro, feijoeiro, mamoeiro, tomateiro, algodoeiro e videira (PONTES et al., 2007).

$\mathrm{Na}$ cultura do morangueiro (Fragaria ananassa Duch), o ácaro-rajado é a principal praga, podendo reduzir a produção de frutos em $80 \%$, quando atinge o ponto máximo de desenvolvimento da população. Esse aracnídeo ataca as folhas desenvolvidas do morangueiro, as quais passam a apresentar manchas branco-prateadas na face inferior, e certa quantidade de teia, na face superior das folhas aparecem áreas inicialmente cloróticas, que posteriormente ficam bronzeadas. Essas folhas secam e caem, com diminuição da área fotossintética e, consequente, redução na produção (SATO et al., 2002).

O controle do ácaro-rajado T. urticae, na cultura do morangueiro, tem sido realizado quase exclusivamente por meio da aplicação de acaricidas sintéticos (SILVA et al., 2009). Entretanto, o uso indiscriminado destes produtos tem proporcionado o rápido desenvolvimento de populações resistentes, a destruição de organismos benéficos e a permanência de elevados níveis de resíduos tóxicos no morango, causando intoxicação de mamíferos (CAVALCANTI et al., 2010).

A utilização de compostos naturais extraídos de plantas tem sido uma alternativa aos inseticidas sintéticos no controle de ácaros (BREDA et al., 2011). Algumas classes de metabólitos secundários vegetais, como rotenóides, piretróides, alcalóides e terpenóides, podem interferir severamente no metabolismo de artrópodes, causando impactos variáveis, como repelência, deterrência alimentar e de oviposição, esterilização, bloqueio do metabolismo e interferência no desenvolvimento, nesse último caso, pode haver retardamento no desenvolvimento do inseto, causando efeito insetistático (ISMAN, 2006).

Outra classe de metabólito que apresenta atividade inseticida, antibacteriana, antifúngica, antiviral e moluscicida é a saponina (SPARG et al., 2004). Estas são estruturalmente constituídas por uma aglicona com esqueleto de triterpeno, esteróide ou alcalóide esteroidal, a qual está ligada a uma ou duas cadeias de açúcar (SIMÕES et al., 1999). As saponinas estão em alto teor nos frutos de Sapindus 
saponaria, árvore da família Sapindaceae (ALBIERO et al., 2001).

A ação de soluções de sabão também tem sido avaliada no intuito de encontrar alternativas ao uso de inseticidas convencionais (PERCIVAL et al., 2012). Essas soluções são indicadas para o controle de insetos de corpo mole, como: pulgões, cochonilas, tripes e ácaros (BUSS; PARK-BROWN, 2002). O controle do ácaro rajado Tetranychus urticae (Koch, 1836) (Acari, Tetranychidae) em Schefflera foi averiguado, em casa de vegetação, utilizando soluções de sabão (OSBORNE, 1984). O uso de soluções de sabão foi estudado frente ao controle de populações de cochonilha (Protopulvinaria pyriformis) em Schefflera arboricola (Hayata) Merr. (Araliaceae) (IMENES et al., 2002). Amiri-Besheli (2010) estudou o efeito de um sabão inseticida comercial (Palizinß) frente ao Phyllocnistis citrella, um lepidóptero da família Gracillariidae, conhecido como "larva minadora de citros".

Considerando os efeitos decorrentes das aplicações de inseticidas convencionais para o controle de $T$. urticae (ácaro rajado) na cultura do morango, objetivou-se com este trabalho avaliar, em condições de laboratório, os efeitos do extrato etanólico dos frutos de S. saponaria e de solução sabão no controle do T. urticae.

\section{MATERIAL E MÉTODOS}

O experimento foi realizado no Setor de Entomologia do Núcleo de Desenvolvimento Científico e Tecnológico em Manejo Fitossanitário de Pragas e Doenças (NUDEMAFI), situado no Centro de Ciências Agrárias da Universidade Federal do Espírito Santo (CCA-UFES), em Alegre, ES, Brasil.

Os indivíduos adultos de $T$. urticae foram coletados no Centro Serrano do Instituto Capixaba de Pesquisa, Assistência Técnica e Extensão Rural (INCAPER). A coleta foi realizada em campo, sob folhas de morango, no município de Domingos Martins, região Serrana do Espírito Santo. No laboratório de Entomologia, os ácaros foram transferidos para folhas de feijão-de-porco (Canavalia ensiformis), contendo, em suas bordas, algodão umedecido. As folhas foram transferidas para pratos plásticos (20 cm de diâmetro) contendo manta acrílica umedecida com água destilada. Os pratos contendo os ácaros foram mantidos em salas climatizadas reguladas à temperatura $25 \pm 1^{\circ} \mathrm{C}, 70 \pm$ $10 \%$ UR e fotofase de $12 \mathrm{~h}$. As folhas foram renovadas em intervalos de 5 a 7 dias. A criação estoque do ácaro rajado foi mantida no setor de Entomologia do NUDEMAFI (HAN et al., 2010).

Neste trabalho foram utilizadas plantas de morango (Fragaria $\mathrm{x}$ ananassa Duch) da variedade Camarosa, fornecidas pelo INCAPER. O solo utilizado para o cultivo das plantas foi analisado no Laboratório de Análises de Solos "Raphael M. Bloise" do CCA-UFES. Posteriormente, foi realizada a adubação e correção deste, seguindo o Manual de Recomendação de Calagem e Adubação para o estado do Espírito Santo, Brasil (PREZZOTI et al., 2007). Em seguida, as plantas de morangueiro foram transferidas para vasos plásticos (1L) contendo o solo corrigido, adubado e foram mantidos em casa de vegetação.

Os frutos maduros de $S$. saponaria, foram coletados no município de Alegre-ES, sendo retirados os endocarpos e descartados as sementes. Os endocarpos foram mantidos por $72 \mathrm{~h}$ a $40^{\circ} \mathrm{C}$, em estufa de ventilação forçada de ar (S480AD, Biopar Equipamentos Eletro-Eletrônicos Ltda., Porto Alegre, Rio Grande do Sul, Brasil). Posteriormente, o material vegetal seco foi moído em moinho de facas (MA-340, Marconi Equipamentos para Laboratório Ltda., Piracicaba, São Paulo, Brasil) com peneira de $0,8 \mathrm{~mm}$ e armazenadas em recipientes plásticos hermeticamente fechados. $\mathrm{O}$ extrato etanólico foi preparado com auxílio de um extrator de óleos e graxas (MA-491, Marconi Equipamentos para Laboratório Ltda., Piracicaba, São Paulo, Brasil), foram usados $5 \mathrm{~g}$ do pó de $S$. saponaria e $50 \mathrm{~mL}$ de álcool etílico absoluto como solvente. $\mathrm{O}$ etanol foi completamente removido do extrato por aquecimento em estufa de ventilação forçada por $48 \mathrm{~h}$ a $40{ }^{\circ} \mathrm{C}$.

Para o preparo da solução sabão, foram transferidos $1 \mathrm{~L}$ de água e $250 \mathrm{~g}$ de hidróxido de sódio $(\mathrm{NaOH})$ para um recipiente em banho de gelo, os quais foram adicionados lentamente e com agitação em movimentos circulares. Após a completa dissolução do $\mathrm{NaOH}$, foram adicionados 1,5L de óleo de soja pré aquecido e, em seguida, 1L de álcool comercial $(92,3 \%(\mathrm{v} / \mathrm{v}))$. A mistura foi agitada até a constatação de mudança de cor e aquisição de consistência. Por último, foi acrescentado 1L de água, sob agitação, até a completa homogeneização da solução sabão em questão.

O extrato etanólico de $S$. saponaria e a solução sabão foram utilizados para o preparo de formulações a 1, 2, 3, 4 e $5 \%(\mathrm{~m} / \mathrm{v})$ utilizando água destilada como solvente.

As folhas de morango foram lavadas com água destilada, imersas em hipoclorito de sódio (1\% (v/v)) por 1 minuto e, novamente, lavadas em água 
destilada. Após esse processo retirou-se das folhas, com auxílio de um cilindro de ferro, discos de 2,0 $\mathrm{cm}$ de diâmetro. Os discos foram acondicionados em placas de Petri $(15 \mathrm{~cm}$ de diâmetro e $5 \mathrm{~cm}$ de altura), forradas com algodão hidrófilo umedecido. Em cada placa de Petri, sobre os discos de folhas, foram colocadas 10 fêmeas adultas fecundadas do ácaro rajado.

Os ácaros foram pulverizados, em Torre de Potter, com $5 \mathrm{~mL}$ das formulações obtidas a partir do extrato etanólico de $S$. saponaria e da solução sabão. A Torre de Potter (pressão de $15 \mathrm{lb} \mathrm{pol}^{-2}$ ) foi aferida para proporcionar um depósito médio de 1,6 $\mathrm{mg} \mathrm{cm}{ }^{-2}$ da solução. Para tal, foi utilizada uma placa de Petri (9 $\mathrm{cm}$ de diâmetro) com papel filtro no fundo e sobre este um apoio de acrílico para a lamínula. Foram utilizadas lamínulas de 24 x 32 $\mathrm{mm}$, totalizando uma área de $7,68 \mathrm{~cm}^{2}$. O peso da lamínula foi avaliado antes e depois da pulverização. Após o procedimento de pulverização, as placas de Petri foram transferidas para câmara climatizada à temperatura de $25,0 \pm 10{ }^{\circ} \mathrm{C}$ e umidade relativa de $70,0 \pm 1,0 \%$ e fotofase de $12 \mathrm{~h}$. Com auxílio de um microscópio-estereoscópio foi observada a mortalidade e o número de ovos. No parâmetro mortalidade foi considerado o ácaro que, com o toque de um pincel, apresentava movimento limitado, ou seja, que se locomovia a uma distância inferior ao próprio corpo (STARK et al., 1997). As avaliações foram realizadas em 24, 72 e 120h após o início do experimento.
O delineamento utilizado foi inteiramente casualizado com 10 repetições. Considerando cada placa de Petri uma repetição contendo 10 ácaros, foram avaliados 100 ácaros por concentração. A relação entre mortalidade, número de ovos e as concentrações das formulações obtidas a partir do extrato etanólico de $S$. saponaria e da solução sabão foi avaliada mediante análise de regressão utilizando o software SIGMA PLOT ${ }^{\circledR}$ 11.0. Os valores de mortalidade foram corrigidos pela fórmula de Abbott (1925) e submetidos à análise de Probit por meio do software Polo- $\mathrm{PC}^{\circledR}$, onde foi estimada a $\mathrm{CL}_{50}$.

\section{RESULTADOS E DISCUSSÃO}

O extrato etanólico de $S$. saponaria promoveu a mortalidade de $T$. urticae em todas as concentrações testadas. Pela análise da Figura 1, observa-se que para uma mesma concentração, houve um considerável acréscimo nas taxas de mortalidade com o aumento do tempo de exposição.

Após $24 \mathrm{~h}$ de exposição, na concentração de $1 \%(\mathrm{~m} / \mathrm{v})$ a mortalidade observada para as fêmeas de $T$. urticae foi de $12 \%$, valor próximo ao encontrado para a testemunha (10\%), nessa mesma concentração, após $72 \mathrm{~h}$ e $120 \mathrm{~h}$, constatou-se $34 \%$ e $56 \%$ de mortalidade, respectivamente. Na primeira avaliação para a formulação de concentração de $5 \%$ $(\mathrm{m} / \mathrm{v})$, observou-se $41 \%$ de mortalidade (24h), sendo $69 \%$ após 72 horas de exposição e finalmente $88 \%$ na última avaliação (120h).

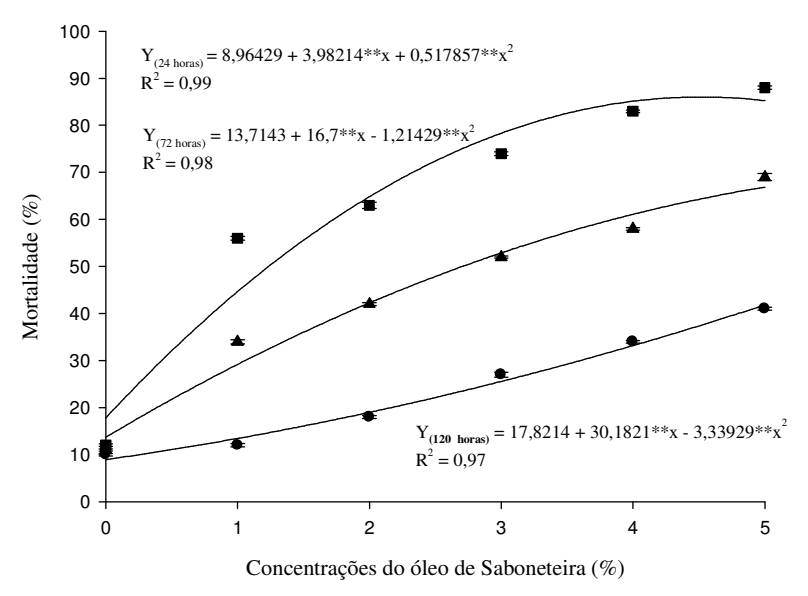

Figura 1. Efeito do extrato etanólico de $S$. saponaria nas concentrações de 1, 2, 3, 4 e $5 \%(\mathrm{~m} / \mathrm{v})$ em relação à mortalidade de fêmeas adultas do ácaro rajado em 24, 72 e 120h após a aplicação.

Quanto ao número de ovos (Figura 2), observou-se que após $24 \mathrm{~h}$ o número médio na testemunha foi de 72,1 , diminuindo para $54,9,36,4$, $33,8,30$ e 27,9 ovos respectivamente, para as concentrações de 1 a $5 \%(\mathrm{~m} / \mathrm{v})$. Na segunda avaliação (após 72h) também foi observada uma redução gradual. $\mathrm{O}$ número médio de ovos observado para testemunha (154,2 ovos) sofreu redução de 97,8 para 69,2 com o aumento da concentração de 2 para $5 \%(\mathrm{~m} / \mathrm{v})$. 
Na última avaliação (após 120h) o número de ovos na testemunha foi de 241,6 ovos, sendo que nas concentrações de 3,4 e $5 \%$ o número de ovos foi de 97,6, 97,0 e 94,4, respectivamente (Figura 2).

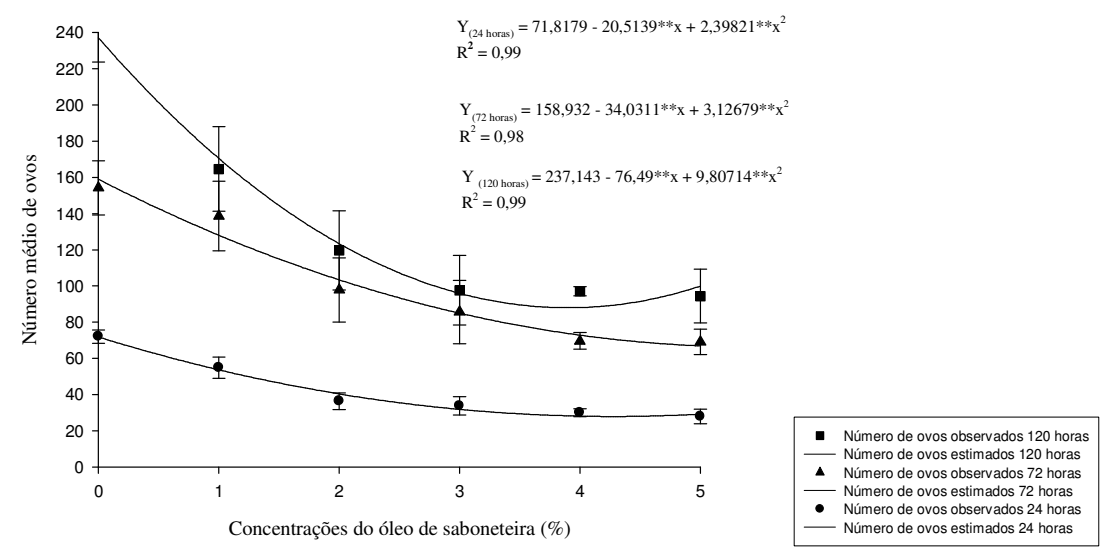

Figura 2. Efeito das formulações contendo extrato etanólico de $S$. saponaria a 1, 2, 3, 4 e $5 \%$ (m/v) no número de ovos de fêmeas adultas de T. urticae em 24, 72 e 120h após a aplicação.

O potencial inseticida de extratos aquosos de $S$. saponaria foi relatado, em Plutella xylostella, após $24 \mathrm{~h}$ de aplicação, na concentração de $10 \%$ $(\mathrm{m} / \mathrm{v})$, observou-se, respectivamente, 100 e $62,5 \%$ de mortalidade para este inseto a partir dos extratos de frutos e folhas de $S$. saponaria (BOIÇA JUNIOR et al., 2005). A inibição da oviposição de Plutella xylostella foi constatada em dois experimentos utilizando extrato aquoso de frutos de $S$. saponaria na concentração de $10 \%(\mathrm{~m} / \mathrm{v})$. Um deles foi analisado durante quatro dias e apresentou efeito deterrente com índice de 100\% (MEDEIROS et al., 2005). Em outro trabalho, após o período de aplicação de $24 \mathrm{~h}$, observou-se a redução do número médio de ovos de 138,0 (testemunha) para 85,0 (JESUS et al., 2011). Santos et al. (2008) trataram folhas de milho com extrato aquoso de $S$. saponaria na concentração de $1 \%(\mathrm{~m} / \mathrm{v})$ e ofereceram como alimento para lagartas da espécie Spodoptera frugiperda, após oito dias, observaram uma redução no peso médio das lagartas em $72,4 \%$.

Em teste com livre chance de escolha utilizando lagartas de terceiro instar de Ascia monuste orseis, discos de folhas de couve foram tratadas com extratos de $S$. saponaria, o efeito repelente foi constatado uma vez que, no decorrer de $24 \mathrm{~h}$ de avaliação, um menor número de lagartas foi atraído $(2,4 \%)$, diferindo significativamente da testemunha $(58,3 \%)$. O extrato aquoso de $S$. saponaria usado no referido experimento foi preparado na concentração de $1,0342 \%(\mathrm{~m} / \mathrm{v})$, valor esse de concentração determinado, previamente, para a $\mathrm{CL}_{50}$ (MEDEIROS; BOIÇA JÚNIOR, 2005).

Extratos etanólicos da casca e caule de $S$. saponaria foram testados em diferentes concentrações sobre larvas de Boophilus microplus, após $48 \mathrm{~h}$, os valores de $\mathrm{CL}_{50}$ e $\mathrm{CL}_{99}$ obtidos foram de $\quad 0,1258 \% \quad(\mathrm{~m} / \mathrm{v})$ e $0,6360 \% \quad(\mathrm{~m} / \mathrm{v})$, respectivamente (FERNANDES et al., 2005). O mesmo extrato foi testado sobre larvas de Rhipicephalus sanguineus em diferentes concentrações, a mortalidade foi observada após $48 \mathrm{~h}$ e os respectivos valores de $\mathrm{CL}_{50}$ e $\mathrm{CL}_{99}$ foram calculados em $0,01994 \%(\mathrm{~m} / \mathrm{v})$ e $0,3922 \%(\mathrm{~m} / \mathrm{v})$ (FERNANDES et al., 2007).

Os extratos de folhas e sementes de $S$. saponaria foram avaliados em relação à oviposição de Callosobruchus maculatus, o pó seco das referidas partes da planta foi misturado com feijãocaupi e colocado em um olfatômetro, um recipiente central contendo adultos de $C$. maculatus, com livre acesso aos tratamentos. Após 48h, os adultos foram retirados e os ovos contados nos grãos, a testemunha apresentou 74,5 ovos e nos grãos tratados com o pó de folhas e de sementes de $S$. saponaria foram observados 11,5 e 8,5 ovos, respectivamente (CASTRO et al., 2010).

Os frutos de $S$. saponaria acumulam grande quantidade de saponinas triterpênicas e sesquiterpênicas, essa classe de substâncias apresenta comprovada atividade inseticida. As saponinas podem atuar nos insetos alterando o comportamento alimentar, causando redução de peso, interferindo na regulação do crescimento, causando distúrbios na duração dos estágios e retardo no desenvolvimento, podem inibir proteases (CHAIEB, 2010), causar citotoxidade (GEYTER et al., 2012), e ainda, por apresentarem propriedades detergentes, formar micelas com lipídeos e interagir com colesterol para formar complexos insolúveis, causando distúrbios na síntese de ecdiesteróides (IKBAL; BEN, 2006). 
Utilizando as formulações de sabão, após 24 $\mathrm{h}$ de experimento, observou-se que houve considerada taxa de mortalidade de fêmeas de $T$. urticae a partir das concentrações de 2 e $3 \%(\mathrm{~m} / \mathrm{v})$, cujos valores foram de 22 e $32 \%$, respectivamente. $\mathrm{Na}$ concentração de $5 \%(\mathrm{~m} / \mathrm{v})$ observou-se $67 \%$ de mortalidade (Figura 3).

Pela análise da Figura 3 observa-se que, após o período de $72 \mathrm{~h}$, a formulação a $3 \%(\mathrm{~m} / \mathrm{v})$ foi suficiente para causar 59\% de mortalidade da população de ácaros. Entretanto, o melhor resultado foi observado para a concentração de $5 \%(\mathrm{~m} / \mathrm{v})$ que apresentou $73 \%$ de mortalidade. $\mathrm{O}$ valor observado para a testemunha foi de $11 \%$.

No período de avaliação de 120 horas, na concentração de $1 \%(\mathrm{~m} / \mathrm{v})$, constatou-se $51 \%$ de mortalidade das fêmeas do ácaro rajado. Nas concentrações de 2,3 e $4 \%(\mathrm{~m} / \mathrm{v})$ foi observado, respectivamente, 63,72 e $78 \%$ de mortalidade. $\mathrm{O}$ valor máximo $(84 \%)$ foi constatado para a concentração de $5 \%(\mathrm{~m} / \mathrm{v})$, (Figura 3).

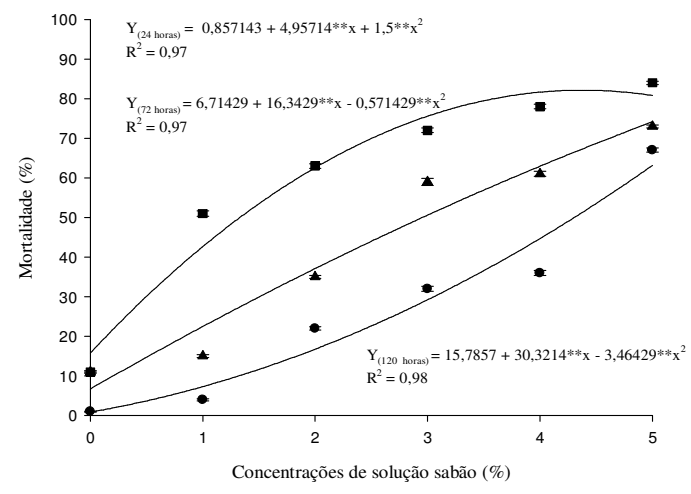

Figura 3. Efeito da solução sabão nas concentrações de 1, 2, 3, 4 e 5\% (m/v) em relação à mortalidade de fêmeas adultas do ácaro rajado em 24,72 e $120 \mathrm{~h}$ após a aplicação.

A solução sabão também apresentou efeito na oviposição de $T$. urticae. Após 24 horas de aplicação, observou-se redução no número médio de ovos com a aplicação das formulações a 1, 2, 3, 4 e $5 \%(\mathrm{~m} / \mathrm{v})$. Estas apresentaram, respectivamente, $88,2,33,0,29,2,21,6$ e 11,2 ovos. O número médio de ovos para a testemunha foi de 101,3 (Figura 4).
Na última avaliação, após 120 horas do início do experimento, observou-se para a testemunha uma média de 349,5 ovos. Este valor diferiu consideravelmente do observado após a aplicação da formulação a $5 \% \quad(\mathrm{~m} / \mathrm{v})$ que proporcionou média de 34,1 ovos.

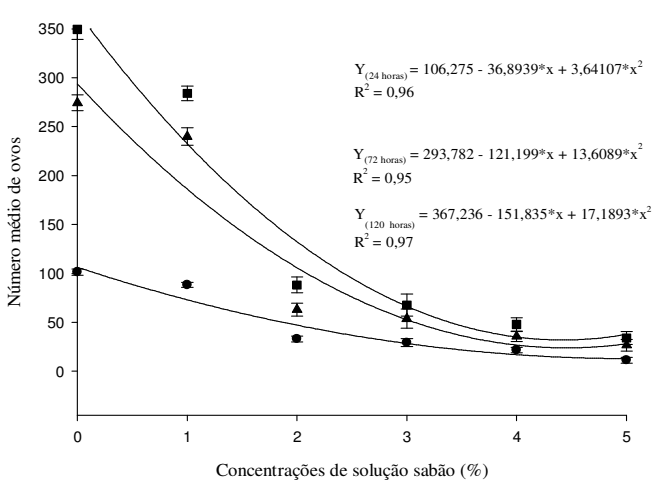

Figura 4. Efeito da solução sabão a 1, 2, 3, 4 e $5 \%(\mathrm{~m} / \mathrm{v})$ no números de ovos de fêmeas adultas de T. urticae em 24, 72 e 120h após a aplicação

Sabões vêm sendo utilizados como inseticidas há mais de 200 anos. Nos últimos anos tem se observado um interesse nesses produtos devido à facilidade e segurança que eles oferecem no momento da aplicação. O sabão obtido a partir de óleo de soja atende essas condições, é de fácil acesso e a sua produção é de baixo custo. As soluções de sabão não apresentam efeito residual e 
têm sido empregadas no controle da mosca-branca, tripes, cochonilhas e ácaros, por efeito de contato (MOREIRA et al., 2006).

Em testes laboratoriais foi constatada a atividade acaricida de dois detergentes comerciais (Quix e Nobla) frente à espécie Panonychus citri (Mcgregor) (Acarina: Tetranychidae), como controle foi usado Fenazaquin $(0,01 \%$ a.i). Os detergentes Quix e Nobla foram utilizados nas concentrações de $0,25 \%$ e $0,45 \%$, respectivamente. Após $24 \mathrm{~h}$ de aplicação, os valores de mortalidade observados para os tratamentos utilizando Quix e Nobla foram, respectivamente, 31,7 e 91,3\%. O controle apresentou $22 \%$ de mortalidade (CURKOVIC; ARAYA, 2004).

Estudos apontam a ação eficiente e promissora das soluções de sabões e detergentes na redução de populações da cochonilha $(P$. pyriformis). Soluções de detergentes a $5 \%(\mathrm{v} / \mathrm{v})$ e de sabão de pedra a $3 \%(\mathrm{~m} / \mathrm{v})$ após 12 horas de pulverização em Schefflera arboricola (Hayata) Merr. (Araliaceae) ocasionaram a morte de $87,48 \%$ e de $83,85 \%$, respectivamente. $\mathrm{O}$ inseticida sistêmico padrão acefato a $1 \%(\mathrm{v} / \mathrm{v})$, usado como controle, foi responsável pela mortalidade de 87,22\% (IMENES et al., 2002).
A associação de detergente neutro a $0,5 \%$ (v/v) com os inseticidas, metomil, betacyfluthrin e dimetoato propiciaram o controle de Bemisia tabaci em 51,50, 55,91 e 64,09\%, respectivamente. Os inseticidas isoladamente obtiveram 8,35, 38,11 e 39,37\% de eficiência, respectivamente (MEDEIROS et al., 2001).

O mecanismo de ação de sabões e de detergentes sobre os insetos ainda não está totalmente elucidado. Esses produtos podem penetrar na cutícula do inseto, dissolvendo-a ou rompendo as membranas celulares, culminando na desidratação e morte do inseto. Pode ocorrer afogamento dos insetos, inibição enzimática, remoção dos indivíduos das folhagens e/ou repelência (ENDERSBY; MORGAN, 1991).

As maiores inclinações das curvas do extrato de saboneteira e de solução sabão indicam que pequenas variações nas concentrações desses tratamentos podem provocar grandes mudanças na mortalidade de $T$. urticae. Embora, o extrato de $S$. saponaria tenha apresentado uma $\mathrm{CL}_{50}(1,18 \%)$, menor que a solução sabão $(1,31 \%)$, ambos, não difereciam entre si, por ter sobreposição do intervalo de confiança (Tabela 1).

Tabela 1. Estimativa do valor de $\mathrm{CL}_{50}$ para o extrato etanólico de $S$. saponaria e de solução sabão em fêmeas de T. urticae. Temperatura: $25 \pm 1^{\circ} \mathrm{C}$, UR de $70 \pm 10 \%$ e fotofase de 12 horas.

\begin{tabular}{ccccccc}
\hline Tratamentos & $\mathbf{C L}_{\mathbf{5 0}}(\boldsymbol{\%})$ & I.C (95\%) & G.L. & n & $\boldsymbol{\chi}^{2}$ & slope \\
\hline S. saponaria & 1,18 & $0,72-1,57$ & 3 & 100 & 2,86 n.s. & $1,55 \pm 0,27$ \\
Solução sabão & 1,31 & $0,80-1,73$ & 3 & 100 & 0,54 n.s. & $1,45 \pm 0,26$ \\
\hline
\end{tabular}

$\mathrm{N}: \mathrm{n}^{\circ}$ de observações/dose. n.s.: não siginificativo.

Estes resultados são favoráveis tanto à utilização do extrato etanólico dos frutos de $S$. saponaria quanto para a solução sabão em programas de manejo fitossinátario do ácaro rajado em morangueiro. Sabões e detergentes apresentam grande potencial a ser usado no controle de insetos em ambientes fechados, domiciliares e comerciais, pois apresentam baixo custo e baixa toxidez (IMENES et al., 2002). Estes fatores justificam a realização de estudos pormenorizados para a busca de métodos mais seguros no controle destas pragas.

\section{CONCLUSÕES}

O extrato etanólico de Sapindus saponaria e a solução sabão em concentrações variáveis entre 1 e 5\%, provocaram mortalidade e interferência na oviposição de fêmeas de Tetranychus urticae, e são promissores para seu manejo.
O extrato etanólico de Sapindus saponaria apresentou maior eficiência do que a solução sabão na mortalidade das fêmeas do ácaro rajado.

A solução de sabão apresentou maior atividade ovicida contra $T$. urticae do que o extrato etanólico de Sapindus saponaria.

\section{AGRADECIMENTOS}

À Fundação de Amparo a Pesquisa e Inovação do Espírito Santo (FAPES); ao Conselho Nacional de Desenvolvimento Científico e Tecnológico (CNPq), pelo apoio financeiro e ao Núcleo de Desenvolvimento Científico e Tecnológico em Manejo Fitossanitário (NUDEMAFI) do Centro de Ciências Agrárias da Universidade Federal do Espírito Santo, pelo apoio técnico e estrutural para o desenvolvimento da pesquisa. 
ABSTRACT: Tetranychus urticae Koch (1836) (Acari: Tetranychidae), known as spider mite is a pest that can reduce fruit production in strawberry up to $80 \%$. The control of the pest by synthetic acaricides has provided the destruction of beneficial organisms and development of resistant populations. As an alternative to traditional control, this study aimed to evaluate the effects of the extract from Sapindus saponaria and soap solution on the oviposition and mortality of females of $T$. urticae. The mites were sprayed with the aid of a Potter Tower, using formulations of extract/soap solution at 1, 2, 3, 4, 5\% (w/v) and assessed at 24, 72 and 120h. It was found that the extract efficiency $\left(\mathrm{LC}_{50}, 1.18 \%\right)$ than the soap solution $\left(\mathrm{LC}_{50}, 1.31 \%\right)$. Regarding the ovicidal activity, the greatest effect was observed with the formulation at $5 \%(\mathrm{w} / \mathrm{v})$ after 120 hours for both the extract $(60.9 \%)$ as for soap solution $(84 \%)$. The results observed in laboratory conditions are favorable to the use of the extract and soap solution to control T. urticae in pest management programs for the strawberry crop.

KEYWORDS: Soapberry. Spider mite. Plant insecticide. Soap.

\section{REFERÊNCIAS}

ABBOTT, W. S. A method of computing the effectiveness of an insecticide. Journal of Economic Entomology, College Park, v. 18, p. 265-267, 1925.

ALBIERO, A. L. M.; BACCHI, E. M.; MOURÃO, K. S. M. Caracterização anatômica das folhas, frutos e sementes de Sapindus saponaria L. (Sapindaceae). Acta Scientiarum, Maringá, v. 23, n. 2, p. 49-560, 2001.

AMIRI-BESHELI, B. Efficacy of chlorpyrifos-methyl, methoxyfenozide, spinosad, insecticidal gel, insecticidal soap and mineral oil on citrus leafminer. Journal of Food, Agriculture \& Environment, Helsinki, v. 8, n. 2, p. $668-671,2010$.

BOIÇA JUNIOR, A. L.; MEDEIROS, C. A. M.; TORRES, A. L.; CHAGAS FILHO, N. R. Efeito de extratos aquosos de plantas no desenvolvimento de Plutella xylostella (L.) (Lepidoptera: Plutellidae) em couve. Arquivos do Instituto Biológico, São Paulo, v. 72, p. 45-50, 2005.

BREDA, M. O.; OLIVEIRA, J. V.; MARQUES, E. J.; FERREIRA, R. G.; SANTANA, M. F. Inseticidas botânicos aplicados sobre Aphis gossypii e seu predador Cycloneda sanguinea em algodão - colorido. Pesquisa Agropecuária Brasileira, Brasília, v. 46, p. 1424-1431, 2011.

BUSS, E. A.; PARK-BROWN, S. G. Natural products for insect pest management. UF/IFAS Publication ENY-350, Florida. Disponível em: http://edis. ifas. ufl. edu/IN197, 2002, acessado em: 10/10/2014.

CASTRO, M. J. P.; SILVA, P. H. S.; SANTOS, T. R.; SILVA, J. A. L. Efeito de pós vegetais sobre a oviposição de Callosobruchus maculatus (Fabr.) (Coleoptera: Bruchidae) em feijão-caupi. Biossay, Piracicaba, v. 5, p. 1-4, 2010 .

CAVALCANTI, S. C. H.; NICULAU, E. S.; BLANK, A. F.; CÂMARA, C. A. G.; ARAÚJO, I. N.; ALVES, P. B. Composition and acaricidal activity of Lippia sidoides essential oil against two-spotted spider mite (Tetranychus urticae Koch). Bioresource Technology, New York, v. 101, p. 829-832, 2010. http://dx.doi.org/10.1016/j.biortech.2009.08.053

CHAIEB, I. Saponins as Insecticides: a Review. Tunisian Journal of Plant Protection, Tunisia, v. 5, p. 39-50, 2010.

CURKOVIC, T.; ARAYA, J. E. Acaricidal action of two detergents against Panonychus ulmi (Koch) and Panonychus citri (Mcgregor) (Acarina: Tetranychidae) in the laboratory. Crop Protection, London, v. 23, p.731-733, 2004. http://dx.doi.org/10.1016/j.cropro.2004.01.003

ENDERSBY, N. M.; MORGAN, W. C. Alternatives to synthetic chemical insecticides for use in crucifer crops. Biological Agriculture and Horticulture, Bicester, v. 8, p. 33-52, 1991.

http://dx.doi.org/10.1080/01448765.1991.9754574 
FERNANDES, F. F.; FREITAS, E. P. S.; COSTA, A. C.; SILVA, I. G. Larvicidal potential of Sapindus saponaria to control the cattle tick Boophilus microplus. Pesquisa Agropecuária Brasileira, Brasília, v. 40, p. 1243-1245, 2005. http://dx.doi.org/10.1590/S0100-204X2005001200013

FERNANDES, F. F.; LELES, R. N.; SILVA, I. G.; FREITAS, E. P. S. Larvicidal potencial of Sapindus saponaria (Sapindaceae) against Rhipicephalus sanguineus (Latreille, 1806) (Acari: Ixodidae). Arquivo Brasileiro de Medicina Veterinária e Zootecnia, Belo Horizonte, v. 59, p. 145-149, 2007.

http://dx.doi.org/10.1590/S0102-09352007000100024

GEYTER, E.; SMAGGHE, G.; RAHBÉC, Y.; GEELEN, D. Triterpene saponins of Quillaja saponaria show strong aphicidal and deterrent activity against the pea aphid Acyrthosiphon pisum. Pest Management Science, London, v. 68, p. 164-169, 2012. http://dx.doi.org/10.1002/ps.2235

HAN, J.; CHOI, B. R.; LEE, S. G.; KIM, S. I.; AHN, Y. J. Toxicity of plant essential oils to acaricidesusceptible and resistant Tetranychus urticae (Acari:Tetranychidae) and Neoseiulus californicus (Acari: Phytoseiidae). Journal of Economic Entomology, College Park, v. 103, p. 1293-1298, 2010.

http://dx.doi.org/10.1603/EC09222

IKBAL, C.; BEN, H. K. Insect growth regulator activity of Cestrum parqui saponins: an interaction with cholesterol metabolism. Communications in Agricultural and Applied Biological Sciences, Belgium, v. 71, p. 489-96, 2006.

IMENES, S. D. L.; BERGMANN, E. C.; FARIA, A. M.; MARTINS, W. R. Registro de alta infestação e efeito de soluções de sabão no controle da cochonilha Protopulvinaria Pyriformis Cockerell, 1894 (Hemiptera, Coccidae) em Schefflera arboricola (Hayata) Merr. (Araliaceae). Arquivos do Instituto Biológico, São Paulo, v. 69 , p. 59-62, 2002.

ISMAN, M. B. Botanical insecticides, deterrents, and repellents in modern agriculture and an increasingly regulated world. Annual Review of Entomology, Palo Alto, v. 51, p. 45-66, 2006.

http://dx.doi.org/10.1146/annurev.ento.51.110104.151146

JESUS, F. G.; PAIVA, L. A.; GONÇALVES, V. C.; MARQUES, M. A.; JÚNIOR, B. A. L. Efeito de plantas inseticidas no comportamento e biologia de Plutella Xylostella (Lepidoptera: Plutellidae). Arquivos do Instituto Biológico, São Paulo, v. 78, p. 279-285, 2011.

MEDEIROS, C. A. M.; JÚNIOR, A. L. B. Efeito da aplicação de extratos aquosos em couve na alimentação de largata Ascia Monuste Orseis. Bragantina, Campinas, v. 4, p. 633-641, 2005. http://dx.doi.org/10.1590/S000687052005000400013

MEDEIROS, F. A. S. B.; BLEICHER, E.; MENEZES, J. B. Efeito do óleo mineral e do detergente neutro na eficiência de controle da mosca-branca por betacyfluthrin, dimetoato e metomyl no meloeiro. Horticultura Brasileira, Brasília, v. 19, p. 74-76, 2001. http://dx.doi.org/10.1590/S0102-05362001000100015

MOREIRA, M. D.; PICANÇO, M. C.; SILVA, E. M.; MORENO, S. C.; MARTINS, J. C. Uso de inseticidas botânicos no controle de pragas. In: VENZON, M.; JÚNIOR, T. J. P.; PALINI, A. Controle alternativo de pragas e doenças, Viçosa: Editora UFV, 2006, p.89-120.

OSBORNE, L. S. Soap spray: an alternative to a conventional acaricide for controlling the twospotted spider mite (Acari: Tetranychidae) in greenhouses. Journal of Economic Entomology, College Park, v. 77, p. 734737, 1984.

PERCIVAL, G. C.; BANKS, J.; KEARY, I. Evaluation of organic, synthetic and physical insecticides for the control of horse chestnut leaf miner (Cameraria ohridella). Urban Forestry \& Urban Greening, Alnarp, v. 11, n. 4, p. 426-431, 2012. 
PONTES, W. J. T.; OLIVEIRA, J. C.S.; CÂMARA, C. A. G. Atividade acaricida dos óleos essenciais de folhas e frutos de Xylopia sericea sobre o ácaro rajado (Tetranychus urticae KOCH). Química Nova, São Paulo, v. 30, p. 838-841, 2007.

PREZOTTI, L. C; GOMES. J. A.; DADALTO. G.G; OLIVEIRA. J. A. de. Manual de recomendação de calagem e adubação para o estado do Espírito Santo - $5^{\text {a }}$ aproximação. Vitória:

SEEA/INCAPER/CEDAGRO, 2007, 305p.

SATO, M. E.; SILVA, M.; GONÇALVES, L. R. Differential toxicity of pesticides to Neoseiulus californicus (McGregor) (Acari: Phytoseiidae) and Tetranychus urticae Koch (Acari: Tetranychidae) on Strawberry.

Neotropical Entomology, Londrina, v. 31, p. 449-456, 2002.

SILVA, V. F.; MALUF, W. R.; CARDOSO, M. G.; NETO, A. C. G.; MACIEL, G. M.; NÍZIO, D. A. C.; SILVA, V. A. Resistência mediada por aleloquímicos de genótipos de tomateiro à mosca-branca e ao ácarorajado. Pesquisa Agropecuária Brasileira, Brasília, v. 44, p. 1262-1269, 2009. http://dx.doi.org/10.1590/S0100204X2009001000008

SIMÕES, C. O.; SCHENKEL, E. P.; GOSMÃO, G.; MELLO, J. C. P.; MENTZ, L. A.; PETROVICK, P. R.

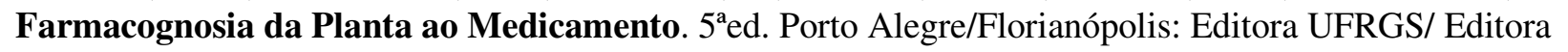
UFSC, 1999.

SPARG, S. G.; LIGHT, M. E.; Van, S. J. Biological activities and distribution of plant saponins. Journal of Ethnopharmacology, Amsterdam, v. 94, p. 219-243, 2004. http://dx.doi.org/10.1016/j.jep.2004.05.016

STARK, J. D.; TANIGOSHI, L.; BOUNFOUR, M.; ANTONELLI, A. Reproductive potential: its influence on the susceptibility of a species to pesticides. Ecotoxicology and Environmental Safety, London, v. 37, p. 273 279, 1997. http://dx.doi.org/10.1006/eesa.1997.1552 